\title{
Competition in science
}

SIR - Most thoughtful observers would agree that "excessive competitiveness" can have many harmful effects on both scientists and science itself (Nature 363, 667 ; 1993). However, excessive competition in science may claim a casualty in addition to those specifically discussed in your article, that is, truth itself. The rush to claim priority may result in the truncation of efforts to establish the validity of the observations that created the excitement in the first place. Yet no one wants the embarrassment of publishing an "exciting" paper which is later shown to be incorrect.

\section{Stephen J. Gall}

Departments of Pathology,

Beth Israel Hospital

and Harvard Medical School,

Boston, Massachusetts 02215, USA

SIR - John Maddox worries, as others have done before, that competition in science is becoming too fierce. Those of us who have endured recently the research selectivity exercise in the United Kingdom will react with hollow laughter to his suggested remedy, sensible though it is, that the link between publication record and reputation should somehow be broken.

Maddox gives details of one aspect of competitiveness, the rush to get into print, which has all the decorum of the opening of the annual sale at a department store. He mentions also the connection with fraud in science. But there are other disadvantages to too much competition. There are concerns about the unit of currency in science; Rosner ${ }^{1}$ drew attention to the increasing prevalence of "assertive sentence titles", which reduce the content of a paper to its title. Crichton ${ }^{2}$ worried that the writers of review articles are not thorough enough, and in doing so alluded to the most serious effect of over-competitiveness, the erosion of time to think.

The scientist was once an all-round thinker, but is now reduced to a searcher for the next item of information. The amount of published work increases rapidly and it is sometimes impossible to keep up in one's own subfield, let alone read more widely. The context or consequences of one's work become subordinate to the facts. There will always be some who prefer to work with this approach, but the present circumstances are forcing it to be the only approach. With that approach, this letter and all comments on the process of science become subordinate to the science itself. I feel this cannot be for the best; yet if asked for evidence it is difficult to set up a testable hypothesis with which to provide it. It is partly this apparently blind rever- ence for facts that has prompted the recent books attacking science ${ }^{3,4}$.

The number of biomedical journals is increasing exponentially ${ }^{5}$, but much published work is never cited ${ }^{6}$ and Hamilton quotes a professor at Massachusetts Institute of Technology saying: "If the bottom $80 \%$ of the literature just vanished, I doubt if the scientific enterprise would suffer." There is immense waste in science. How much waste is necessary to ensure that real progress is made? Does science really have to proceed at the pace it is being pushed? And how much of the waste is because of competition?

Neville W. Goodman

University Department of Anaesthesia, Southmead Hospital,

Bristol BS10 5NB, UK

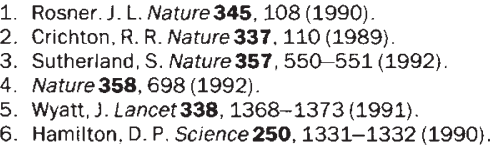

\section{Insurance risks}

SIR - I am perfectly comfortable with the arguments advanced about the ethical issues involved in genetics with one exception. You ask "why should [insurance companies] also not discriminate against, say, people with the particular structure of the LDL receptor known to be responsible for early-onset heart disease?"1 In fact, however, there is an enormous literature available in the legal world on why it is unwise to allow insurance companies to set their rates on the basis of immutable characteristics such as race or other unchanging attributes (see, for example, refs $2-4)$; indeed, the various laws of the United States frequently prohibit insurance companies from using this type of data when setting rates.

Essentially it is argued that the essence of insurance is to spread risks of certain illnesses and diseases throughout society and not to burden those who bear the exclusive risk with its full costs. This social policy should seem to prevent precisely that type of rate setting data from being used. This type of law is quite distinguishable from the legally permissible policy of raising rates for those who engage in voluntary pleasurable activity that increases their risk of illness, such as smoking.

\section{Michael Broyde}

Department of Religion,

Emory University,

Atlanta, Georgia 30322, USA

1. Nature 364, 97 (1993).

2. Lowe, R. Drake Law Rev. 40, 507 (1991).

3. Miller, J. Dickinson Law Rev. 93, 729 (1989)

4. Kolata, G. Science 232, 317 (1986).

\section{Cite unsound}

SIR - Like most other scientists, from time to time I receive papers to review. It has been my practice to check all the references that I can easily get hold of, checking that both the bibliographical information and also the cited data or opinions are correct. If a paper has been revised several times, it is almost inevitable that the interpretation or context of some citations will change (and should be checked before anyone else sees the paper). However, I have been surprised at how many citations are just plain wrong.

For example, a citation to insect damage never mentioned insects in general or in particular. A paper cited as comparing grazing versus hay production consisted entirely of hand-cut plants grown in pots in a controlled environment chamber, while one that was claimed to show the effects of phosphorus and potassium fertilizer only looked at nitrogen. I have even had someone quoting himself as finding the opposite from what he actually found. A colleague tells me he was once asked why he did not quote the standard reference on a topic. His response was that, despite being widely quoted, it did not exist.

Is careless citation common to other areas of research or is it peculiar to agronomy? How do authors expect us to trust their data, which we cannot check, if their citations, which we can check, are treated so cavalierly? I urge all authors to check references carefully, and reviewers to reject papers with careless citation, to try to cut down on the amount of misinformation entering the system.

\section{R. R. Symons}

Agriculture Canada,

Brandon Research Station,

POBOX 1000A, RR3,

Brandon, Manitoba,

CanadaR7A 5 Y 3

\section{Fetal tissue}

SIR - The Commentary article by Bianchi, Bernfield and Nathan (Nature 363, $12 ; 1993)$ is mistaken regarding the scope of the five-year moratorium on US federal support for fetal tissue transplantation research. The moratorium curtailed the use of electively aborted human fetal tissue in therapeutic transplantation research, but it did not stop the use of human fetal tissue in basic research. In fact, during those five years, the National Institutes of Health funded approximately $\$ 8$ million annually in basic research using human fetal tissue. Human development and cell differentiation were topics of a number of those studies.

\section{Sarah Carr}

Science Policy Studies Center,

National Institutes of Health,

Bethesda, Maryland 20892, USA 